\title{
Commentary
}

\section{Palliative Care Training for Work in an Austere Environment after a Natural Disaster}

\author{
Annekathryn Goodman, MD, MPH'; Lynn Black, MD, MPH² \\ 'Department of Obstetrics and Gynecology, Massachusetts General Hospital, MGH Global Disaster Response, Harvard Medical School, Boston, \\ MA 02 I I 4, USA
}

${ }^{2}$ Department of Medicine, Massachusetts General Hospital, MGH Global Disaster Response, Harvard Medical School, Boston, MA 02 I I 4, USA

\section{"Corresponding author}

Annekathryn Goodman, MD, MPH

Professor of Obstetrics, Department of Obstetrics and Gynecology, Division of Gynecologic Oncology, Reproductive Biology Harvard, Medical School Massachusetts General Hospital, Gillette Center for Women's Cancers, Yawkey 9E, 55 Fruit St., Boston, MA 02I I4, USA; Tel. I-6I 7-724-5242;

Fax: I-6|7-724-6898; E-mail: agoodman@mgh.harvard.org

\section{Article information}

Received: April 16 ${ }^{\text {th }}$ 2018; Accepted: April 23 ${ }^{\text {rd }}, 2018$; Published: March 23 ${ }^{\text {rd }}, 2018$

\section{Cite this article}

Goodman A, Black L. Palliative care training for work in an austere environment after a natural disaster. Palliat Med Hosp Care Open J. $2018 ; 4$ (I): I0-I3. doi: $10.17140 / \mathrm{PMHCOJ}-4-128$

\section{ABSTRACT}

Healthcare professionals who work in the disaster field confront many challenges to the care of victims of natural disasters. Disaster responders face destroyed physical infrastructures, scarce supplies, and a limited trained peer group. During a mass casualty event, healthcare responders will encounter disaster victims who are triaged to the "expectant" category of care because either their injuries are not survivable or the resources needed to care for them surpass what is available. Responders have not been traditionally trained to administer palliative care in a disaster setting. This commentary examines the challenges that responders face in caring for dying patients in the field and advocates for basic palliative care training prior to deploying to a disaster.

\section{Key words}

Disaster response; Palliative care training; Triage; Expectant management.

\section{CASE STUDY}

M.C.

was a 79-year-old woman who was rescued from the rubble after being buried for 48 hours after January 12, 2010, Haitian earthquake. She had several fractures of her arms and legs, and extensive crush injuries leading to acute renal failure. Her arms and legs were covered in maggots. She was brought to the United States Field hospital in Port Au Prince. She was awake, confused, and delirious. Any movement caused extreme distress. She was alone. The rescuers could not find any of her family members or friends. After a medical assessment, the team felt that she would not survive her devastating injuries and she was triaged to the expectant category of care.

The nursing team placed her in a plastic body bag that was zipped up to her chest to contain the extensive maggot burden on her extremities. An intravenous line was placed in her subclavian vein and morphine was administered every 30 minutes as needed. She was placed in the tent near the team leader station and was checked every 20 minutes. She expired twelve hours after arriving.

\section{INTRODUCTION}

A natural disaster such as an earthquake, flood, or hurricane can cause significant loss of life, destruction of property, and displacement of surviving populations. The mandate of medical teams who enter a disaster zone is to administer immediate medical care to the survivors. ${ }^{1}$ In a mass casualty event, medical teams are trained to evaluate injured survivors based on the severity of their injuries, the acuity of their needs, and whether they will be able to survive from their injuries. Well-established triage systems categorize injuries based on an urgent need for care and survivability. For instance, a common system includes the following categories: "immediate" where the victim requires immediate life-saving treatment; "urgent" where the individual requires medical intervention 
within six hours; "delay" where the survivor has minor injuries or non-life threatening injuries and their care can be delayed; and "expectant" where the individual will not survive their injuries or where the extent of interventions required would overwhelm the medical system and take away resources for the treatment of other people with more survivable injuries. ${ }^{2}$

Beyond the identification of patients to the "expectant" category, medical responders receive little training about how to care for immanently dying patients during a disaster. This commentary reviews the challenges to care for this category of patient, the stresses on the medical providers, and some basic palliative interventions to provide comfort to the patient and their family members during this catastrophic time.

\section{CHALLENGES TO THE CARE OF THE “EXPECTANT" PATIENTS}

In a natural disaster or man-made conflict zone, there may be limited medications to treat pain, and to manage anxiety and distress. Local resources can be disrupted and supplies brought in by outside responders may be inadequate and delayed. For instance, during Hurricane Sandy, there was a disruption of methadone maintenance programs for existing opioid users and concern that opiate pain management for new victims of the hurricane would be unavailable. ${ }^{3}$ Oxygen availability and airway management capability may be inadequate for the need. For instance, during the first week after the Haitian earthquake, a field hospital had limited oxygen availability and a choice needed to be made as to which of the three critically ill patients in their hospital would receive the remaining oxygen supply. In another example of extensive burn injuries after the mass casualty event of the Pope Air Force base disaster, airway management challenges and lack of sufficient clinical personnel challenged the ability to care for so many severely injured people. ${ }^{5}$

Destruction of buildings and of existing medical infrastructure after a disaster can lead to limited hospital bed availability and limited structures to protect these patients from the weather and the extremes of temperature. While not specifically addressing "expectant" patients, Ho et al identify crowding in temporary shelters as a significant problem for survivors after the 2015 Nepali earthquake. ${ }^{6}$ After the Fukushima nuclear crisis, a loss of medical infrastructure led to a shift in palliative care from inpatient to home care.

\section{CHALLENGES FOR THE MEDICAL PROVIDERS}

The first responders to a disaster are members of the affected community. ${ }^{8}$ One stress for healthcare workers of an impacted community is the balance of their own needs and needs for taking care of their families and taking care of victims of their community. ${ }^{9}$ First responders face safety and security risks while working in the field after a disaster that can lead to immediate personal physical injury and the late effects of post-traumatic stress disorder (PTSD). ${ }^{10}$ For instance, one study reported up to a $23 \%$ rate of PTSD in responders after the World Trade Center Terror attacks. ${ }^{11}$ In contrast, another report comments on the power of peer support among responders to prevent mental health effects of disaster response. ${ }^{12}$ Medical providers can experience moral distress at not being able to provide care to "expectant" patients. ${ }^{13,14}$

While there is little literature on disaster responders and palliative care training, a survey of surgeons identified several key challenges to discussing end-of-life issues with patients and family members. The majority reported no formal training in palliative care $(76.1 \%)$ plus unrealistic expectations among families along with cultural barriers to communication. ${ }^{15}$

\section{BASIC PALLIATIVE INTERVENTIONS FOR EXPECTANT PATIENTS}

The case study at the beginning of this commentary describes the creative caring of an elderly woman who was mortally wounded in the Haitian earthquake. It was not possible to treat her crush injuries or renal failure and the medical team chose to focus on pain management and being present during this woman's final hours. The morphine alleviated her pain and anxiety. However, it was difficult to communicate with the patient because of her delirium and other family members could not be found. Her condition was very distressing to watch. In retrospect, a team briefing and debriefing would have supported the nurses who primarily cared for her. In addition, chaplaincy support at the end of this woman's life and for the healthcare team could have discussed the meaning of M.C.'s tragic and lonely final hours.

Codification of normative and operational guidelines for healthcare responders have contributed to the professionalization of both humanitarian aid and medical interventions after a disaster. ${ }^{1}$ The World Health Organization (WHO) has an essential medicine list that should be brought by medical teams into the disaster setting. ${ }^{16}$ Basic pain management of all patients should be a mandatory component of the medical response. Common symptoms in palliative care include anxiety, depression, agitation, breathlessness, and gastrointestinal distress. Table 1 lists the medications for palliative care as recommended by the WHO.

\begin{tabular}{|c|c|}
\hline Indication & Medication \\
\hline Pain & $\begin{array}{l}\text { - Acetylsalicylic Acid, } \\
\text { - Paracetamol, } \\
\text { - Ibuprofen, } \\
\text { - Codeine, } \\
\text { - Fentanyl, } \\
\text { - Methadone } \\
\text { - Morphine } \\
\text { - Amitriptyline }\end{array}$ \\
\hline Anxiety \& Depression & $\begin{array}{l}\text { - Diazepam } \\
\text { - Fluoxetine } \\
\text { - Amitriptyline }\end{array}$ \\
\hline Agitation & $\begin{array}{l}\text { - Haloperidol } \\
\text { - Midazolam }\end{array}$ \\
\hline Breathlessness & - Dexamethasone \\
\hline Nausea \& Vomiting & $\begin{array}{l}\text { - Cyclizine } \\
\text { - Dexamethasone } \\
\text { - Hyoscine Hydrobromide } \\
\text { - Metoclopramide } \\
\text { - Ondansetron }\end{array}$ \\
\hline Diarrhea & - Loperamide \\
\hline Constipation & $\begin{array}{l}\text { - Docusate } \\
\text { - Senna }\end{array}$ \\
\hline \multicolumn{2}{|c|}{ This table is adapted from the essential medicine list WHO, 2017. ${ }^{15}$} \\
\hline
\end{tabular}




\begin{tabular}{|ll|}
\hline Table 2. Training Topics in Palliative Care Prior to Disaster Deployment \\
\hline Symptom Management Protocols & - Pain \\
& - Anxiety \\
& - Respiratory distress \\
& - Delirium \\
& - Nausea and Vomiting \\
\hline Spiritual Management & - Grief \\
\hline Cultural Training specific to the location of the disaster & - Identify meaning \\
& - The meaning of death in the culture \\
\hline Training for difficult conversations & - Delivering Bad News \\
\hline Self-Care Training & - Managing a grieving family \\
& - Develop a system for debriefing \\
& - Develop a buddy system \\
\hline
\end{tabular}

Medical team members should receive basic training in the delivery of bad news. The palliative presence and acknowledgement of the situation can bring comfort. Active listening skills should be another component of the communication skill set. ${ }^{17}$ Table 2 lists predeployment training topics for medical teams to increase palliative care expertise in the field.

An on-site designated ethics task force within the team to discuss difficult dilemmas can reduce the team distress of not actively treating expectant patients. ${ }^{4}$ Other field hospitals have reported their experiences of triaging patients to palliative care. In the Philippines, after the Typhoon Haiyan, the Israeli team described their triage system for patients seen with advanced cancers. ${ }^{18}$

There have been many programs used to train healthcare personnel in communication and palliative care interventions in the non-disaster setting. ${ }^{19}$ For instance, simulation and case studies have been a successful tool to develop competency. ${ }^{20}$

\section{CONCLUSION}

There are many barriers to the care of those victims of disaster who will not survive. Challenges include a loss of medical infrastructure and scarce medical and physical resources. Additionally, disaster responders have not been routinely trained to manage dying patients in the field.

The experience of palliative care training for non-palliative care specialists can be instructive for the development of palliative care training for medical care responders after disasters. Applying standards, identifying goals of care for the expectant patient, communication to the patient, if possible, and family members, if available, can help reduce the suffering of this group of devastatingly vulnerable patients. In addition, peer support, on-site discussions and debriefing, and problem-solving when resources are limited will help alleviate moral distress among the providers.

\section{CONFLICTS OF INTEREST}

The authors declare that they have no conflicts of interest.

\section{REFERENCES}

1. Learning J, Guha-Sapir D. Natural disasters, armed conflict, and public health. N Engl J Med. 2013; 369: 1836-1842. doi: 10.1056/ NEJMra1109877

2. Sasser SM, Hunt RC, Faul M, et al. Centers for isease Control and Prevention (CDC). Guidelines for field triage of injured patients. Recommendations of the National Expert Panel on Field Triage, 2011. MMWR Recommendations \& Reports. 2012; 61(RR-1): $1-20$.

3. Matusow H, Benoit E, Elliott L, Dunlap E, Rosenblum A. Challenges to opioid treatment programs after hurricane sandy: Patient and Provider Perspectives on Preparation, Impact, and Recovery. Subst Use Misuse. 2018; 53(2): 206-219. doi: 10.1080/10826084.2016.1267225

4. Goodman A, Black L. The Challenge of allocating scarce medical resources during a disaster in a low-income country: A case study from the 2010 Haitian earthquake. Palliat Med Hosp Care Open J. 2015; 1(1): 24-29. doi: 10.17140/PMHCOJ-1-105

5. King BT, Peterson WC. The care of thermally injured patients in operational, austere, and mass casualty situations. Wilderness Environ Med. 2017; 28(2S): S103-S108. doi: 10.1016/j.wem.2017.03.011

6. Ho MLL, Lim JZM, Tan MZW, et al. Humanitarian Assistance and Disaster Relief mission by a tripartite medical team led by the Singapore Armed Forces after the 2015 Nepal earthquake. Singapore Med J. 2016; 57(8): 426-431. doi: 10.11622/smedj.2016132

7. Ozaki A, Tsubokura M, Leppold C, et al. The importance of family caregiving to achieving palliative care at home: a case report of end-of-life breast cancer in an area struck by the 2011 Fukushima nuclear crisis: A case report. Medicine, 2017; 96(46); e8721. doi: 10.1097/MD.0000000000008721

8. Harris C, McCarthy K, Liu EL, et al. Expanding understanding of response roles: an examination of immediate and first responders in the United States. Int J Environ Res Public Health. 2018; 15(3): 
534. doi: 10.3390/ijerph15030534

9. Morris AM, Ricci KA, Griffin AR, Heslin KC, Dobalian A. Personal and professional challenges confronted by hospital staff following Hurricane Sandy: A qualitative assessment of management perspectives. BMC Emergency Medicine. 2016; 16: 18. doi: 10.1186/ s12873-016-0082-5

10. Reissman DB, Howard J. Responder safety and health: Preparing for future disasters. Mt Sinai J Med. 2008; 75(2): 135-141. doi: $10.1002 / \mathrm{msj} .20024$

11. Luft BJ, Schechter C, Kotov R, et al. Exposure, probable PTSD and lower respiratory illness among World Trade Center rescue, recovery and clean-up workers. Psychological Medicine. 2012; 42(5): 1069-1079. doi: 10.1017/S003329171100256X

12. Kranke D, Weiss EL, Heslin KC, Dobalian A. "We are disaster response experts": A qualitative study on the mental health impact of volunteering in disaster settings among combat veterans. Social Work in Public Health. 2017; 32(8): 500-509. doi: doi: 10.1080/19371918.2017.1365033

13. Hunt MR. Establishing moral bearings: Ethics and expatriate health care professionals in humanitarian work. Disasters. 2011; 35(3): 606-622. doi: 10.1111/j.1467-7717.2011.01232.x

14. Goodman A. From Boston to Nepal: How to treat suffering without resources. Humanitarian Health Ethics. 2017. Web site. https://humanitarianhealthethics.net/2017/05/04/from-bostonto-nepal-how-to-treat-suffering-without-medical-resources/. Ac- cessed April 15, 2018.

15. Suwanabol PA, Reichstein AC, Suzer-Gurtekin ZT, et al. Surgeons' perceived barriers to palliative and end-of-life care: A mixed methods study of a surgical society. J Palliat Med. 2018; doi: 10.1089/jpm.2017.0470. [Epub ahead of print]

16. World Health Organization (WHO), (2017). Essential medicines in emergencies. Web site. http://www.who.int/hac/techguidance/pht/essentialmed/en/. Accessed April 15, 2018.

17. Hunt MR, Schwartz L, Sinding C, Elit L. The ethics of engaged presence: A framework for health professionals in humanitarian assistance and development work. Dev World Bioeth. 2014; 14(1): 47-55. doi: 10.1111/dewb.12013

18. Marom T, Segal D, Erlich T, Tsumi E, Merin O, Lin G. Ethical and clinical dilemmas in patients with head and neck tumors visiting a field hospital in the Philippines. Am J Disaster Med. 2014; 9(3): 211-219. doi: 10.5055/ajdm.2014.0172

19. Lakin JR, Koritsanszky LA, Cunningham R, et al. A systematic intervention to improve serious illness communication in primary care. Health Aff (Millwood). 2017; 36(7): 1258-1264. doi: 10.1377/ hlthaff.2017.0219

20. Smith MB, Macieira TGR, Bumbach MD, et al. The use of simulation to teach nursing students and clinicians palliative care and end-of-life communication: A systematic review. Am J Hosp Palliat Care. 2018: 1049909118761386. doi: 10.1177/1049909118761386. [Epub ahead of print] 